\title{
ANALISIS PENGARUH PERUBAHAN UKURAN CAM LOBE LIFT TERHADAP PERFORMA PADA MESIN OTTO EMPAT LANGKAH
}

\author{
Nicholas Kurniawan $^{1}$, Arka D. Soewono ${ }^{2,}$ a) , Isdaryanto Iskandar $^{2}$ \\ ${ }^{1}$ Mahasiswa Program Studi S1 Teknik Mesin Universitas Katolik Indonesia Atma Jaya, \\ Jl. Raya Puspiptek Serpong, Tangerang Selatan-Banten, Indonesia, 15320 \\ ${ }^{2}$ Dosen Tetap Program Studi S1 Teknik Mesin Universitas Katolik Indonesia Atma Jaya, \\ Jl. Raya Puspiptek Serpong, Tangerang Selatan-Banten, Indonesia, 15320 \\ a) arka.atmajaya@gmail.com (corresponding author)
}

\begin{abstract}
Abstrak
Perubahan ukuran lift pada cam lobe dipelajari untuk melihat pengaruhnya terhadap nilai efisiensi volumetris dan performa pada mesin Otto empat langkah satu silinder berkapasitas $150 \mathrm{cc}$. Pengujian dilakukan dengan membandingkan cam standar sebesar 7,36 mm dengan cam yang memiliki lift lebih tinggi, yaitu 8,24 mm dan $8,53 \mathrm{~mm}$. Pengujian dilakukan dengan software ANSYS untuk mendapatkan efisiensi volumetris, sedangkan performa diukur menggunakan dinamometer. Dari perhitungan dan pengujian, kedua cam modifikasi yang digunakan berhasil meningkatkan efisiensi volumetris dan performa dari mesin. Cam dengan lift 8,53 mm meningkatkan efisiensi volumetris dari 78,51\% menjadi 84,1\% dan performa dari 15,36 WHP ke 15,76 WHP pada 9000 rpm jika dibandingkan dengan cam standar.
\end{abstract}

Kata kunci: Cam lobe, efisiensi volumetris, performa, daya, torsi.

Abstract

The modification of cam lobe lift value was studied to observe its effects on the volumetric efficiency and performance of a 4-stroke Otto engine with a displacement of $150 \mathrm{cc}$. The testing was done by comparing the standard cam lobe with 7,36 mm lift and two other cam lobes with a higher lift, which is 8,24 mm and 8,53 mm. ANSYS software was used as a method to acquires the volumetric efficiency value, while a dynamometer was used to measures the performance. From the calculation and testing that has been done, the usage of both modification cam lobes increase the volumetric efficiency and performance of the engine. Compared with the standard cam, the cam with $8,53 \mathrm{~mm}$ lift result in an increase of volumetric efficiency from $78,51 \%$ to $84,1 \%$ and performance from 15,36 WHP to 15,76 WHP at $9000 \mathrm{rpm}$.

Keywords: Cam lobe, volumetric efficiency, performance, power, torque.

\section{PENDAHULUAN}

Dalam kendaraan bermesin siklus Otto, jumlah udara dan bensin yang masuk ke dalam ruang bakar adalah hal yang penting. Udara masuk melalui filter udara dan mengalir melalui saluran intake, sedangkan bensin akan diinjeksi oleh fuel injector pada daerah sebelum katup intake. Pada langkah hisap, katup intake akan terbuka. Kemudian udara dan bensin akan terhisap masuk ke dalam ruang bakar dengan jumlah dan rasio tertentu.

Pergerakan katup intake terjadi karena adanya dorongan oleh cam lobe yang berputar pada porosnya, yaitu camshaft. Pergerakan katup intake terjadi secara sinkron dengan pergerakan piston dari TMA ke TMB karena komponen-komponen ini terhubung secara mekanis. Kemampuan suatu mesin untuk menghisap udara di sekitarnya disebut sebagai efisiensi volumetris. Pada kendaraan mesin Otto empat langkah, efisiensi volumetris selalu menurun ketika putaran mesin meningkat. Pada putaran mesin yang rendah, gerakan membuka dan menutup dari katup intake masih dapat diikuti oleh udara sehingga udara masih dapat masuk ke ruang bakar semaksimal mungkin. Namun, pada putaran mesin tinggi, gerakan dari katup dan piston menjadi terlalu cepat sampai tidak memberikan waktu yang cukup kepada udara untuk mengalir semaksimal mungkin agar dapat masuk ke ruang bakar. Hal ini mengakibatkan jumlah udara yang masuk ke ruang bakar menjadi jauh lebih sedikit daripada 
jumlah udara yang seharusnya dapat masuk ke ruang bakar, sehingga efisiensi volumetrisnya menurun.

Salah satu upaya yang dapat dilakukan untuk meningkatkan efisiensi volumetris pada putaran mesin tinggi adalah dengan mengganti camshaft dengan cam lobe yang memiliki lift lebih besar dari standar. Ukuran lift yang lebih besar dapat mendorong katup intake lebih jauh dan membuat bukaannya semakin besar sehingga udara lebih mudah mengalir. Jika udara lebih mudah mengalir, jumlah udara yang dapat masuk ke dalam ruang bakar ketika putaran mesin tinggi akan semakin banyak, sehingga membantu meningkatkan efisiensi volumetrisnya. Peningkatan efisiensi volumetris ini diharapkan dapat meningkatkan daya dan torsi pada putaran mesin tinggi.

\section{METODE PENELITIAN}

Pada penelitian ini, mesin motor yang digunakan adalah mesin motor Honda dengan tipe K56. Mesin ini merupakan mesin Otto empat langkah satu silinder berkapasitas $150 \mathrm{cc}$. Untuk spesifikasi lengkapnya dapat dilihat pada Tabel 1.

Tabel 1. Spesifikasi mesin K56.

\begin{tabular}{|c|c|}
\hline Parameter & Spesifikasi \\
\hline Tipe Mesin & 4 Langkah DOHC \\
\hline Kapasitas Mesin & $149,16 \mathrm{cc}$ \\
\hline Sistem Suplai Bahan Bakar & PGM-FI \\
\hline Diameter (bore) & $57,3 \mathrm{~mm}$ \\
\hline Langkah (stroke) & $57,8 \mathrm{~mm}$ \\
\hline Tipe Transmisi & Manual 6 percepatan \\
\hline Rasio Kompresi & $11,3: 1$ \\
\hline Daya Maksimum & $17,1 \mathrm{PS}$ pada $9000 \mathrm{rpm}$ \\
\hline Torsi Maksimum & $14,4 \mathrm{Nm}$ pada $7000 \mathrm{rpm}$ \\
\hline Diameter cam lobe & $27 \mathrm{~mm}$ \\
\hline Diameter Katup In & $22 \mathrm{~mm}$ \\
\hline
\end{tabular}

Pada penelitian ini, cam lobe yang digunakan harus cam lobe buatan khusus yang hanya berbeda lift-nya saja dari cam lobe standar, sedangkan parameter lainnya seperti diameter, timing open, timing close dan overlap harus tetap sama. Hal ini dilakukan supaya hasil penelitian tetap valid. Hasil penelitian yang ada hanya dipengaruhi oleh perubahan lift pada cam lobe. Spesifikasi cam lobe yang digunakan dapat diperhatikan pada Tabel 2.

Tabel 2. Spesifikasi cam lobe standar dan modifikasi.

\begin{tabular}{|c|c|c|}
\hline \multirow{2}{*}{ Parameter } & \multicolumn{2}{|c|}{ Spesifikasi } \\
\hline & Standar & Modifikasi 8,53 \\
\hline Maximum Lift & $7,36 \mathrm{~mm}$ & $8,53 \mathrm{~mm}$ \\
\hline Open & \multicolumn{2}{|c|}{$7^{\circ}$ sebelum TMA } \\
\hline Close & \multicolumn{2}{|c|}{$38^{\circ}$ setelah TMB } \\
\hline Overlap & \multicolumn{2}{|c|}{$9^{\circ}$} \\
\hline Diameter & \multicolumn{2}{|c|}{$27 \mathrm{~mm}$} \\
\hline Durasi lift & \multicolumn{2}{|c|}{$225^{\circ}$} \\
\hline
\end{tabular}

Pengukuran performa dilakukan dengan dinamometer Dynojet 250i. Pada setiap pengujian, hanya cam lobe saja yang diubah. Untuk parameter lainnya seperti keadaan lingkungan sekitar, suhu, tekanan, oktan bahan bakar, dan parameter ECU, diusahakan dan dipertahankan agar tidak berubah banyak. Hal ini bertujuan agar satu-satunya yang memengaruhi hasil ukur 
hanya berasal dari perubahan cam lobe. Pengujian dilakukan pada hari yang sama dengan selang waktu antarpercobaan sekitar satu jam.

Pengujian efisiensi volumetris dilakukan dengan menggunakan software ANSYS. Penggunaan ANSYS diperlukan untuk pengujian air flow karena pengujian dengan alat seperti flowbench tidak memungkinkan. Titik pengujian yang ingin diperhitungkan ada pada daerah setelah katup intake. Hal tersebut tidak dapat dilakukan oleh flowbench. Penggunaan ANSYS lebih fleksibel karena titik perhitungan dapat dilakukan di mana saja. Untuk parameter yang digunakan dalam simulasi ANSYS dapat dilihat pada Tabel 3. Untuk menyederhanakan geometri yang digunakan pada ANSYS, maka digunakan nilai valve lift, yang memiliki faktor pengali dari nilai lobe lift karena rocker arm $^{[1]}$. Volume akan dihitung ketika volume ruang bakar berada pada nilai maksimal, yaitu ketika piston di posisi titik mati bawah (TMB) $)^{[2]}$.

Tabel 3. Parameter simulasi ANSYS.

\begin{tabular}{|c|c|}
\hline Parameter & Keterangan \\
\hline \multicolumn{2}{|l|}{ Parameter mesh } \\
\hline Tipe mesh & Hybrid \\
\hline Reference size $(\mathrm{mm})$ & 0,947 \\
\hline $\operatorname{Min}$ mesh size $(\mathrm{mm})$ & 0,474 \\
\hline Max mesh size $(\mathrm{mm})$ & 4,735 \\
\hline Curvature normal angle (deg) & 30 \\
\hline Number of inflation layers & 8 \\
\hline Chamber size (mm) & 1,421 \\
\hline \multicolumn{2}{|l|}{ Boundary Condition } \\
\hline ice-outlet & $\begin{array}{l}\text { Type }=\text { pressure-outlet; } \\
\text { Gauge pressure }=-5000 ; \\
\text { Temperature }=300\end{array}$ \\
\hline ice-inlet-inplenum1 & $\begin{array}{l}\text { Type }=\text { pressure-inlet } \\
\text { Gauge pressure }=-5000 \\
\text { Temperature }=300\end{array}$ \\
\hline \multicolumn{2}{|l|}{ Surface Monitor } \\
\hline Report type & Volume flow rate \\
\hline Surfaces & $\begin{array}{l}\text { Ice-inlet-inplenum1 } \\
\text { Ice-outlet }\end{array}$ \\
\hline
\end{tabular}

Setelah mendapatkan nilai flow rate, maka akan dihitung nilai efisiensi volumetrisnya menggunakan Persamaan 1.

$$
\eta_{v}=\frac{V_{t h}}{V_{I V C}}
$$

Dengan:

$\eta_{v}:$ efisiensi volumetris [\%]

$V_{t h}$ : volume udara riil yang terhisap

$V_{I V C}$ : volume udara teoritis yang seharusnya dapat terhisap

\section{HASIL DAN PEMBAHASAN}

Dari hasil pengujian menggunakan software simulasi ANSYS, didapatkan nilai volume flow rate pada setiap bukaan maksimum valve lift tertentu, yaitu dengan pengaturan valve lift 10,3 $\mathrm{mm}, 11,54 \mathrm{~mm}$, dan 11,94. Simulasi dijalankan pada putaran mesin $9000 \mathrm{rpm}$. Dapat diperhatikan bahwa nilai valve lift yang digunakan berbeda dengan nilai lobe lift yang biasanya disebutkan. Hal ini dikarenakan software ANSYS yang hanya memiliki input berupa valve lift, dan nyatanya mesin motor yang digunakan untuk uji coba memiliki rocker arm dengan rasio 1,4:1, sehingga besar valve lift adalah 1,4 kali lebih besar daripada lobe lift.

Pada Tabel 4, dapat diperhatikan bahwa pada percobaan pertama, lobe lift standar sebesar 7,36 mm memberikan nilai flow rate sebesar 18,6 CFM. Lalu pada percobaan selanjutnya dengan lobe lift 8,24 mm, dihasilkan flow rate sebesar 19,75 CFM yang artinya meningkat sebesar $6 \%$ dari percobaan pertama. Kemudian pada percobaan ketiga dengan lobe lift 8,53 
mm, dihasilkan flow rate sebesar 19,92 CFM yang artinya meningkat sebesar 0,8\% dari percobaan kedua.

Tabel 4. Besar Nilai Volume Flow Rate pada Ukuran Lobe Lift Tertentu

\begin{tabular}{|c|c|c|c|c|}
\hline No. & $\begin{array}{c}\text { Lobe Lift } \\
(\mathbf{m m})\end{array}$ & $\begin{array}{c}\text { Valve Lift } \\
(\mathbf{m m})\end{array}$ & $\begin{array}{c}\text { Volume Flow Rate } \\
\left(\mathbf{m}^{\mathbf{3}} / \mathbf{s}\right)\end{array}$ & $\begin{array}{c}\text { Volume Flow Rate } \\
(\mathbf{C F M})\end{array}$ \\
\hline $\mathbf{1}$ & 7,36 & 10,304 & $8,78 \times 10^{-3}$ & 18,6 \\
\hline $\mathbf{2}$ & 8,24 & 11,536 & $9,32 \times 10^{-3}$ & 19,75 \\
\hline $\mathbf{3}$ & 8,53 & 11,942 & $9,40 \times 10^{-3}$ & 19,92 \\
\hline
\end{tabular}

Peningkatan flow rate ini dapat dilihat pada Gambar 1. Besar flow rate didekat katup intake terlihat meningkat sedikit. Hal ini dikarenakan katup in yang mampu membuka lebih jauh. Bukan saja hanya meningkatkan flow rate, modifikasi ini nampaknya juga mengubah pola pergerakan swirl yang terjadi di dalam ruang bakar. Pola swirl ini cukup berpengaruh dalam hal performa sebab semakin besar tingkat swirl akan membuat bahan bakar dan udara dapat bercampur lebih merata, menghasilkan pembakaran yang lebih sempurna.

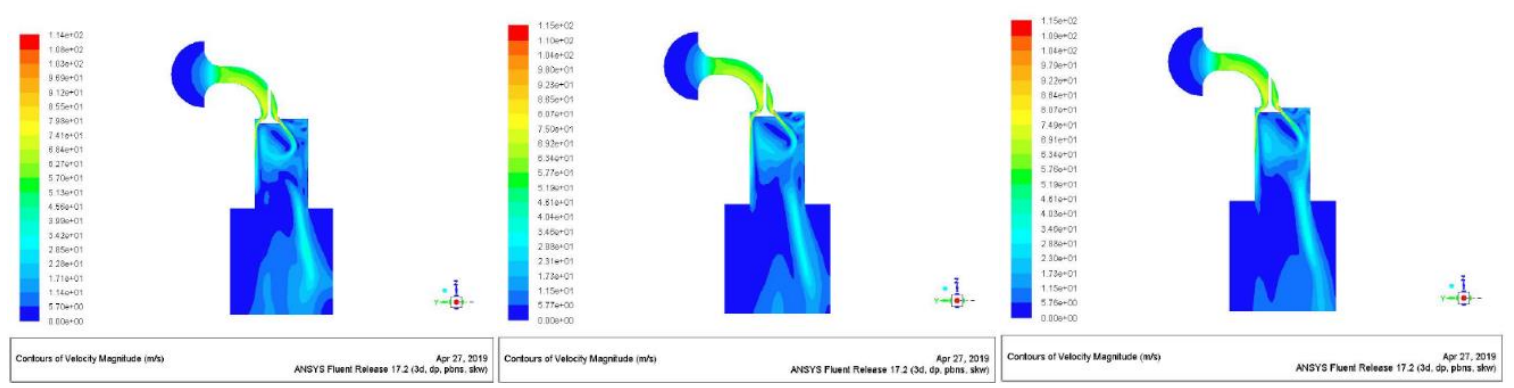

Gambar 1. Hasil simulasi flow rate dengan cam lobe 7,36 mm, 8,24 mm, dan 8,53 mm.

Peningkatan flow rate ini menunjukan adanya kenaikan efisiensi volumetris ketika menggunakan cam lobe dengan lobe lift yang lebih besar, seperti yang ditunjukkan pada Tabel 5.

Tabel 5.Data Efisiensi Volumetris pada Ukuran Lobe Lift Tertentu

\begin{tabular}{|c|c|c|c|c|}
\hline No. & $\begin{array}{c}\text { Volume Teoritis } \\
\text { Mesin }\end{array}$ & $\begin{array}{l}\text { Lobe Lift } \\
\quad(\mathrm{mm})\end{array}$ & $\begin{array}{c}\text { Volume Udara Aktual yang } \\
\text { Terhisap } \\
\text { (cu.ft) }\end{array}$ & $\begin{array}{c}\text { Efisiensi } \\
\text { Volumetris }\end{array}$ \\
\hline 1 & \multirow{3}{*}{$\begin{array}{c}149,0483 \mathrm{cc} \\
\text { atau } \\
5,264 \times 10^{-3} \mathrm{cu} . \mathrm{ft}\end{array}$} & 7,36 & $4,133 \times 10^{-3}$ & $78,51 \%$ \\
\hline 2 & & 8,24 & $4,389 \times 10^{-3}$ & $83,38 \%$ \\
\hline 3 & & 8,53 & $4,427 \times 10^{-3}$ & $84,1 \%$ \\
\hline
\end{tabular}

Secara teoritis, penggunaan cam lobe dengan lobe lift yang lebih besar dapat membuat udara lebih mudah masuk dan efisiensi volumetris akan terus bertambah. Ditambah lagi adanya semburan bahan bakar yang lebih banyak yang diberikan oleh. Dengan meningkatnya efisiensi volumetris dari sebuah mesin, maka performa mesin tersebut seharusnya ikut meningkat. Namun, jika pengujian terus dilakukan dengan ukuran lobe lift lebih besar lagi, maka kemampuan injeksi dari injektor bahan bakar juga perlu diperhatikan. Injektor tersebut belum tentu mampu menyemprotkan jumlah bahan bakar yang cukup agar rasio bensin dan udara sesuai AFR pada ECU. Jika udara terlalu banyak dan bensin yang diinjeksikan tidak cukup, mesin akan masuk ke dalam mode yang terlalu lean. Hal ini dapat memberi efek buruk kepada mesin. Salah satunya adalah suhu pembakaran di atas batas normal.

Dari hasil pengujian menggunakan dinamometer, didapatkan grafik yang menunjukan hubungan antara daya dan torsi terhadap putaran mesin dengan cam lobe yang memiliki lobe lift tertentu, yaitu 7,36 mm, 8,24 $\mathrm{mm}$, dan $8,53 \mathrm{~mm}$. 
Pertama, grafik "hubungan antara daya dan torsi terhadap putaran mesin" akan diamati secara terpisah berdasarkan perbedaan ukuran lobe lift. Pada Gambar 2(a), dapat dilihat bahwa penggunaan cam lobe yang memiliki lobe lift sebesar 7,36 mm ("STANDART_7") menghasilkan daya maksimal sebesar 15,36 WHP pada $8950 \mathrm{rpm}$ dan torsi maksimal sebesar 9,96 lb.ft atau 13,5 Nm pada $7030 \mathrm{rpm}$. Pada pengujian kedua, penggunaan ukuran lobe lift yang lebih besar, yaitu 8,24 mm ("LIFT1_18"), dapat memberikan peningkatan daya maksimal sebesar 0,31 WHP, sehingga daya maksimalnya menjadi 15,67 WHP pada 9020 rpm dan torsi maksimal tetap 9,96 lb.ft atau 13,5 Nm pada $7590 \mathrm{rpm}$, seperti yang ditunjukkan pada Gambar 2(b). Pada pengujian ketiga, penggunaan ukuran lobe lift yang lebih besar dari pengujian kedua, yaitu 8,53 mm ("LIFT2_25"), memberikan peningkatan daya maksimal sebesar 0,09 WHP dari pengujian kedua atau 0,40 WHP dari pengujian pertama, dan torsi maksimal sebesar 0,06 Nm dari pengujian pertama dan kedua, sehingga nilai dari daya maksimalnya adalah 15,76 WHP pada $9010 \mathrm{rpm}$ dan torsi maksimal sebesar $10 \mathrm{lb} . \mathrm{ft}$ atau 13,56 Nm pada $7500 \mathrm{rpm}$, seperti yang ditunjukkan pada Gambar 2(c).

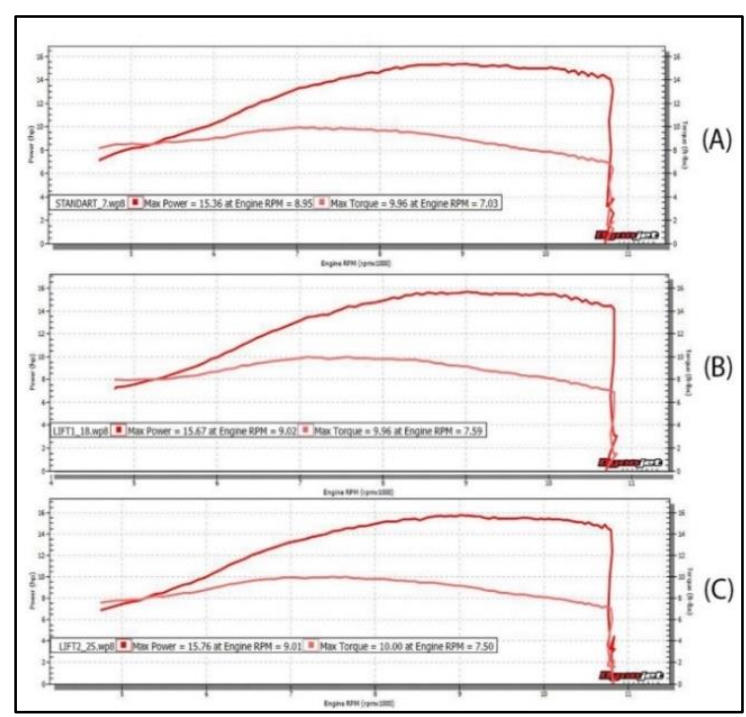

Gambar 2. Grafik hubungan antara daya dan torsi terhadap putaran mesin dengan cam lobe tertentu.

Tiga pengujian menggunakan dinamometer ini telah membenarkan hipotesis yang menyatakan bahwa peningkatan efisiensi volumetris dari pembesaran ukuran lobe lift dapat meningkatkan performa pada mesin motor yang digunakan dalam uji coba ini. Peningkatan performa juga dipengaruhi oleh sistem kerja closed loop dari ECU. Ketika udara yang masuk lebih banyak, sensor oksigen pada bagian exhaust akan mendeteksi adanya kelebihan udara. Data tersebut akan dibaca oleh ECU, kemudian ECU akan mencoba menyeimbangkan campuran yang baru agar rasio campuran tersebut kembali sama seperti nilai AFR yang disimpan dalam ECU, yaitu dengan menyemburkan lebih banyak bahan bakar.

Pada pengujian ini, yang paling berpengaruh terhadap perubahan ukuran lobe lift ini ada pada putaran tinggi. Hal ini dapat dilihat pada Gambar 3, di mana pada putaran mesin menengah (7000-8000 rpm) selisih performa tidak terlalu banyak terlihat. Namun ketika mulai memasuki putaran mesin tinggi (di atas $8000 \mathrm{rpm}$ ), fungsi dari penggunaan lobe lift yang lebih besar baru terlihat. Lobe lift berukuran $8,53 \mathrm{~mm}$ menghasilkan tenaga yang lebih besar dibandingkan dengan lobe lift standar pada putaran mesin yang sama sampai mencapai 
limiter. Pada putaran mesin rendah (4500-7000 rpm), terlihat bahwa hal yang terjadi justru adalah kebalikannya. Penggunaan cam lobe dengan lobe lift $8,53 \mathrm{~mm}$ menghasilkan performa yang lebih rendah dari cam lobe standar. Fenomena ini sebenarnya memang sudah diprediksi akan terjadi dan dapat disebabkan oleh beberapa hal. Pertama adalah ketika suatu suku cadang dalam bagian mesin diganti dengan suku cadang yang lebih dioptimasi untuk putaran mesin tertentu, maka pasti ada bagian atau range putaran mesin yang dikorbankan. Seperti contohnya penggunaan cam lobe yang lebih besar untuk mengoptimasi performa pada putaran mesin tinggi, maka performa pada putaran mesin rendah akan dikorbankan. Kedua adalah pengaturan AFR yang tidak sesuai. Sebenarnya, jika AFR disesuaikan, maka kemungkinan besar masalah ini dapat terselesaikan, tetapi memang sengaja tidak dilakukan agar tidak menambah variabel yang memengaruhi perubahan nilai efisiensi volumetris dan performa mesin.

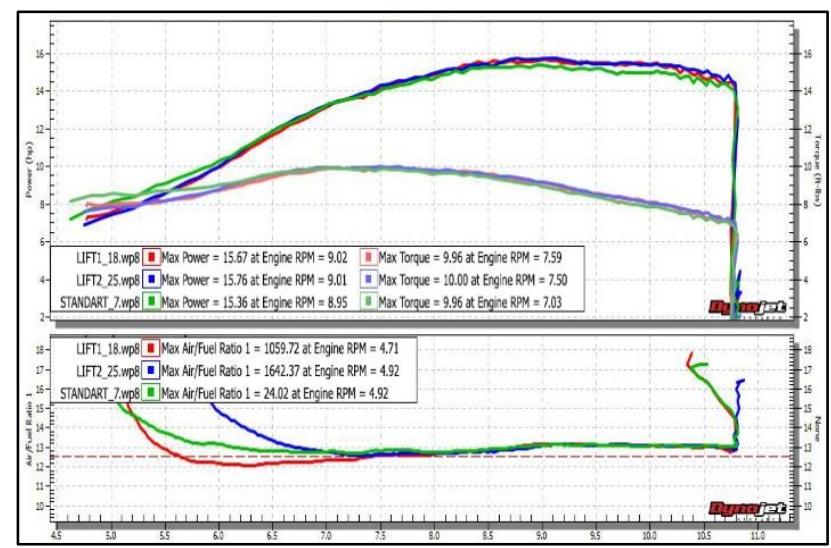

Gambar 3. Grafik gabungan hubungan antara daya dan torsi terhadap putaran mesin dengan cam lobe tertentu.

Dalam sistem motor pembakaran dalam, jika dilihat dari sisi kimianya, dua senyawa yang paling berpengaruh untuk menghasilkan daya dalam proses pembakaran adalah oksigen dan bahan bakar. Dari peningkatan efisiensi volumetris tersebut, jumlah oksigen adalah faktor yang paling berpengaruh dalam peningkatan performa motor [4]. Ketika jumlah udara yang dihisap lebih banyak, artinya jumlah oksigen yang terhisap dan masuk ke dalam ruang pembakaran juga lebih banyak. Jumlah oksigen yang lebih banyak akan meningkatkan laju pembakaran dan mempersingkat ignition delay sehingga proses yang dibutuhkan dari sejak busi memercikan api sampai proses pembakaran selesai menjadi lebih cepat ${ }^{[5]}$. Selain itu, suhu pembakaran akan meningkatkan nilai specific heat ratio dari siklus pembakaran ${ }^{[4]}$. Peningkatan specific heat ratio akan meningkatkan laju konversi dari energi panas menjadi energi gerak. Lalu, berdasarkan rumus efisiensi termal, peningkatan dari specific heat ratio juga akan meningkatkan nilai dari efisiensi termal itu sendiri ${ }^{[6]}$. Karena brake power dipengaruhi juga oleh efisiensi termal, maka peningkatan dari efisiensi termal akan meningkatkan brake power ${ }^{[7,8]}$. Karena Brake Power meningkat, maka Work Power atau Work Horsepower (WHP) juga ikut meningkat. Hal inilah yang menyebabkan peningkatan dari efisiensi volumetris dapat meningkatkan nilai WHP.

Selain itu, ketika udara yang masuk ke dalam ruang bakar lebih banyak dari keadaan standar, artinya mesin akan mengompresi volume udara yang lebih banyak dalam volume ruang bakar yang sama, sehingga tekanan pembakaran akan membesar juga. Dalam keadaan ini, temperatur kerja dari mesin tentunya akan meningkat. Tetapi peningkatan tersebut belum sampai ke tahap di mana panasnya akan berbahaya bagi mesin. Selain temperatur, gaya yang dihasilkan dari ledakan pada langkah kerja juga akan meningkat sebab jumlah partikel yang 
dikompresi awalnya lebih banyak juga. Peningkatan gaya ini akan meningkatkan torsi dan daya pada mesin.

\section{KESIMPULAN}

Dari hasil percobaan dan analisis yang telah dilakukan, maka didapatkan kesimpulan bahwa perubahan ukuran lift pada cam lobe dapat berpengaruh kepada nilai efisiensi volumetris dan performa pada mesin Otto empat langkah berkapasitas $150 \mathrm{cc}$, terutama pada saat putaran mesin tinggi. Peningkatan ukuran lift pada cam lobe dari 7,36 $\mathrm{mm}$ ke $8,53 \mathrm{~mm}$ pada mesin Otto empat langkah satu silinder ini meningkatkan efisiensi volumetris dari 78,51\% ke 84,1\% dan daya dari 15,36 WHP ke 15,76 WHP.

Peningkatan ukuran lift dari 7,36 $\mathrm{mm}$ ke 8,24 $\mathrm{mm}$ memberikan pengaruh yang lebih signifikan daripada peningkatan dari $8,24 \mathrm{~mm}$ ke $8,53 \mathrm{~mm}$ karena peningkatannya memang tidak bersifat linear. Ada beberapa faktor yang dapat membatasi seperti kemampuan mekanis dari mesin dan profil dari saluran intake udara.

\section{UCAPAN TERIMA KASIH}

Penulis ingin mengucapkan terima kasih kepada Bapak Isdryanto Iskandar, M.Sc. dan Bapak Arka Soewono, Ph. D. yang memberikan bimbingan dalam menganalisis pengaruh perubahan cam lobe lift terhadap perfoma pada mesin Otto empat langkah.

\section{REFERENSI}

Husain S.M., Sheikh, S., (2013): Rocker Arm: - A Review, International Journal of Innovative Research in Science, Engineering and Technology, vol. 2(4), hal. 11201126.

Pesic, R., Taranović, D., Petković, S., et al., (2013): Aspects of Volumetric Efficiency Measurement for Reciprocating Engines, Thermal Science, vol. 17(1), hal. 35-48.

Autobiz Tech Tips, (2012): Torque and Power, IE: Autobiz

Baskar, P., dan Senthilkumar, A., (2015): Effects of Oxygen Enriched Combustion on Pollution and Performance Characteristics of a Diesel Engine, Engineering Science and Technology, an International Journal, vol. 9(2016), hal. 438-443.

Jeevahan, J., Poovannan A., et al., (2017): Effect of Intake Air Oxygen Enrichment for Improving Engine Performance and Emissions control in Diesel Engine, International Journal of Ambient Energy, vol. 40(1), hal. 96-100.

Papagiannakis, R., Rakopoulos, D.C., dan Rakopoulos, C.D., (2018): Evaluation of the Air Oxygen Enrichment Effects on Commbustion and Emissions of Natural Gas/Diesel Dual-Fuel Engines at Various Loads and Pilot Fuel Quantities, Energies, vol. 11(11), hal. 3028.

Rajkumar, K., dan Govindarajan P., (2011): Impact of Oxygen Enriched Combustion on the Performance of a Single Cylinder Diesel Engine, Front Energy, vol. 5(4), hal. 398403. 
Rajkumar, K., dan Govindarajan P., (2010): Experimental Investigation of Oxygen Enriched Air Intake on Combustion Parameters of a Single Cylinder Diesel Engine, International Journal of Engineering Science and Technology, vol. 2(8), hal. 36213627. 